\title{
Thinking through global crime and its research agendas
}

\author{
Tim Hall and Vincenzo Scalia
}

\section{What do we mean when we talk about global crime?}

Approximately 11:45, Thursday 24 August 2017, Naples central train station. One of us (Tim) is travelling from Rome to his brother's wedding which is taking place near Reggio Calabria in southern Italy the next day. The train waits at Naples for approximately 15 minutes before it is scheduled to move on to its next stop. The scene on the train is noisy and chaotic, a contrast to the tranquillity of the journey from Rome. Large numbers of passengers have departed the train at Naples and a larger number are boarding. Many are talking loudly, some are shouting into mobile phones as they struggle to find their seats. One woman standing near his left shoulder is particularly loud. At one point she shouts at top volume into her mobile phone. He turns around in annoyance. A couple of seconds later he glances up at the luggage rack above the carriage windows. The black bag he had placed there as the train left Rome is gone. He turns around immediately and the woman on the phone has disappeared. He looks back up the carriage in the opposite direction but sees no one exiting the carriage with his bag. On the platform a whistle is blown and the train begins to depart. The bag contained his passport, and that of his wife who is travelling with him, his mobile phone, his bank and credit cards, house keys and travel documents which gave his home address and dates of travel. There is much panic, then considerable sympathy and kindness from the other passengers in the carriage as the realization that he has been robbed sinks in.

When the train pulled into Reggio Calabria some hours later the long process of unpicking the consequences of the robbery began. His Italian sister-in-law took him to the local Carabinieri station so that a report of the robbery could be obtained. Banks and credit card companies were telephoned to cancel cards. The British Embassy in Rome was contacted, and an appointment was booked so that he could obtain emergency travel documents to return to the UK a few days later. Alternative travel and accommodation arrangements were booked to get him and his wife back to Rome in time for their Monday morning appointment at the British Embassy. His mobile telephone company was reached to cancel the stolen phone. Initial contact with travel insurance companies was made. The subsequent untangling of the consequences of this momentary encounter in a Naples train station took over two months and enrolled spaces in many different countries. 
A simple mapping of the actors connected to this crime illustrates the transnational dimensions of a crime that would be classed, within a classical criminological reading, as nothing more than an example of an everyday, local, volume crime. The banks who provided the debit cards that were stolen on the train were Lloyds and National Westminster (NatWest). Lloyds Bank is a British bank, one of the largest retail banks in the UK. Lloyds has extensive international operations, although dealing with the theft of the debit card fell within the remit of its UK banking operation and involved contact with one of Lloyds' 18 UK call centres. NatWest is also a UK bank and again the stolen card was dealt with through its UK call centre network. His credit card was provided by John Lewis, a UK retail company, but was a Mastercard, a company that describe itself as a 'leader in global digital payment' (https://www.mastercard.co.uk/en-gb.html). Mastercard is an American multinational headquartered in New York and St Louis Missouri with operations worldwide. Mastercard is a key player in facilitating the global credit card payment network that has become a mundanely routine part of life for many today. His mobile phone was provided by $\mathrm{O}_{2}$, the trading name of Telefónica UK, which is headquartered in Slough in southern England but is part of the Spanish multinational Telefónica which operates globally. Telefónica's headquarters are in Madrid and cancelling the mobile phone took (numerous) calls to its call centres that appeared to be located in South Africa, although the actual locations of O2's call centres are somewhat opaque, as entering $+\mathrm{O}_{2}+$ "call centre" + locations into an internet search engine will reveal. It is likely that these call centres were managed by a company called Capita, headquartered in London. Tim eventually had to contact the $\mathrm{CEO}$ of $\mathrm{O}_{2}$ at the Slough head office to address the inconsistencies and payment problems he experienced after trying to cancel his stolen phone. The insurance policy through which he attempted to claim the losses he had suffered as a result of the robbery was provided by Worldwide Internet Insurance Services Ltd, trading as Cover For You, which is licensed in Gibraltar, a common tactic for UK companies seeking to take advantage of its low corporate tax rate, although Cover For You has a head office in London. The policy was underwritten by AXA UK which has a head office in London but which is part of AXA, a French multinational headquartered in the 8th arrondissement of Paris. His insurance claim was dealt with by Rightpath Claims whose head office is in Rochford, a town in Essex in southeast England. Finally, Trenitalia, the Italian national train company he used to get back to Rome earlier than originally planned for the meeting at the British Embassy, is headquartered in Rome, while UNA Hotels and Resorts, which he used for additional nights of accommodation in Rome, has its head office in Milan. All of these companies were enrolled, albeit in small ways, in the event of Tim being robbed in Naples.

Beyond being struck by the irony of a supposed expert in organized crime being robbed in Naples, this incident highlights something about the complexities of concepts of crime in a global age. The robbery described above was, at first glance, a classic example of local crime. There appears to have been no obvious connections between the gang who took the bag and any organized crime groups in Naples. There have been, for example, no repercussions in terms of identity theft, and the 
house keys that were in the stolen bag were not immediately Fed Ex'd to London so that the house could be broken into and the new car, that was sitting on the driveway, stolen. However, many aspects of its consequences crossed national boundaries and had international connections. What, then, does the example above tell us about the notion of global crime? Viewing crime as it has tended to be viewed traditionally as a discrete event and through local-global binaries offers only truncated perspectives. The robbery Tim experienced was over in minutes within the spatial confines of a busy railway carriage but had a hinterland that was networked across many countries.

Thinking of this event in relational terms ties together a number of spatially distant places through the networks of connections that are now typical of the daily lives and interactions of many, although it should be stressed not all, in the Global North. A map of the connections from this event, and one which does not even access the more obscure connections that underlie many of the actors involved, for example, to offshore banking sites beyond Gibraltar, would destabilize the notion that this was simply a case of local crime. It suggests actually that few crimes now can be thought of purely as local, discrete events and that perhaps traditional ways of thinking through crime in a global age need some critical re-evaluation. This task - and the contributors to this collection approach it in many different ways and from a number of perspectives - is the key aim of this book.

\section{Thinking through global crime - academic debates}

Discussions about global crime, particularly in relation to organized crime, have developed only in recent times. The reason at the heart of this late development might be that the label 'global' started being used only after the fall of the Berlin Wall, in 1989. The collapse of the Eastern Bloc is supposed to have brought about a boost in the internationalization of economic and cultural exchange, as well as a higher degree of cultural hybridization. Following these crucial worldwide changes, Anthony Giddens, in 1991, in his book The Consequences of Modernity, forged the term globalization to refer to five specific dimensions: the world capitalist economy; the transformation of nation states; the world military order; the international labour division; and culture. The dimensions of globalization prove valid theoretical lenses to focus on globalized crime: how do criminal organizations draw advantage from this global integration of economy and culture?

The debate about global crime is as recent as that about globalization. There are three main reasons for such a late development. Firstly, the existence of criminal organization has been doubted for many years. On the one hand, it was denied in those areas where organized crime was most likely to exist, such as in Sicily (Santino, 2000). On the other hand, it was not clear what a criminal organization was, how it differed from a gang, a brotherhood, or groups like the Freemasons. Anthropologists such as Anton Blok (1974) defined the mafia not as an organization but as a cluster of independent individuals (the Mafioso) who acted as brokers 
between the local and the global community. The interpretation of organized crime provided by Blok, though trying to analyse 20 years before Giddens the relationships between local and global communities, did not acknowledge the existence of criminal organizations, and did not articulate the concept of mediation as it did not specify what sort of role the Mafioso played within the global economy. Secondly, when the existence of organized crime was recognized it followed a judicial interpretation fraught with ethnic prejudices. We are referring to the definition of organized crime as an alien conspiracy, fuelled by the Kefauver US Congress Committee in 1952. This view, on the one hand, admitted that a phenomenon such as organized crime existed, but on the other hand provided an ethnically biased interpretation: that of the same old ethnic groups, such as Italians, Irish and Jews, being labelled as the ones who swelled the ranks of criminal organizations, acting as an internal threat to the free and democratic American post-World War II society. An updated version of the Kefauver Committee's view is provided by Loretta Napoleoni, an Italian-born journalist based in London. According to Napoleoni (2005), there is an overlap between terrorist and criminal organization, which share the aim of destroying the Western social fabric by carrying out their illegal activities.

The third reason for this belated development relates to globalization: only since 1989 have both public opinion and academics become widely aware of the fact that criminal organizations can pass national borders and create a wide-ranging network of activities, thus drawing advantage from the liberalization of exchanges, deregulations of finance, and, finally, from technological advancement. The debate on global crime developed out of the sociological concept of globalization and most of the authors who covered this topic, and who we will be mentioning in the following pages, are sociologists. Their work has been influential also for criminologists. The only criminologists who have provided an original interpretation of organized crime and globalization are David Nelken (1998) and Vincenzo Ruggiero (1996).

In order to reach a definition of organized crime, and to reflect upon the possibilities of its global expansions, we have to wait until 1993. This is the year when Diego Gambetta, an Italian-born researcher who was then a full professor in Oxford, published his study about the Sicilian Mafia, a book which proved to be influential among all scholars who have worked on organized crime. This book, despite its many theoretical and empirical flaws that have been explored elsewhere (Scalia, 2010, 2016), provided academics with two important conceptual tools. The first one concerns the definition of organized crime, which Gambetta envisages as an industry of private protection, with criminal organizations operating like companies in legal markets to make profits by enhancing their reputation through the use of a specific brand. This latter aspect relates to the second tool Gambetta has provided: the relationship between organized crime and its expansion outside its original contexts. The brand of private protection, Gambetta argues, can be used only in those contexts where its reputation has been established for a long time. Consequently, it is not possible for organized crime to expand outside its natural boundaries; in other words, outside those contexts where the lack of public trust 
requires the supply of private protection. When public trust is high, both on a horizontal level (that is, between social actors) and on a vertical level (between society and the central government), there is no need for private protection, and it will be difficult for crime to grow to a transnational or global scale. How is it possible to explain, then, the expansion of the Sicilian Mafia, the Calabrian 'Ndrangheta and the Neapolitan Camorra in northern Italy? Or the presence of Latin American Narcos and Russian Solncevo in London? Gambetta uses a medical metaphor, suggesting that it is a matter of contagion. Healthy societies, where a market economy provides a reasonable allocation of resources and the state grants a minimum acceptable degree of security to every citizen, will resist the infiltration of organized crime. As a consequence of this, criminal organizations can transplant their own activities through the use of violence, as well as by spreading their illegal activities, such as drug trafficking, within an uncorrupted social fabric. Gambetta's view sound like an updating of Kefauver's alien conspiracy, but this is the minimum flaw such a view denotes. The economic, cultural and social trends of recent years have brought about a blending of legal and illegal worlds, sometimes making it difficult to draw a line between the two (see Hudson, Chapter 2 this volume, for example). Moreover, coercion has been but marginal, as investments by criminal organizations have often proved to be profitable for the legal market.

Federico Varese (2011) has attempted to reshape the theory of private protection to fit it into a global perspective. In Varese's view, mafias are on the move. As their business grows, criminal organizations seek other opportunities to expand their illegal profitable activities. It is a matter of a transplant rather than one of contagion, as the creation and development of illegal activities where they did not exist before means to introduce something external to the social pattern of the areas where new mafias try to expand. Criminal transplants can be successful only under some specific local conditions: limited public attention to the issue of organized crime; a weak penal legislation which makes it easier for criminal organizations to dodge both controls and repression; weak organized crime groups (or strong, but inclined to make deals); and vacuums in the social fabric caused by economic or political crisis. To cut a long story short, the analysis of global crime provided by Federico Varese, unlike Gambetta, accepts the possibility that globalization can bring about the expansion of organized crime in areas where it was unthinkable until recently. Moreover, Varese, does not regard this process as the result of an imposed colonization, but rather as the consequence of the ability that criminal organizations have to calculate and plan their operational strategies. Finally, Varese enhances the importance of local elements for the migration and transplant of mafias to be successful. The more global the world grows, the more local dimensions matter.

In exploring the importance of local and global variables for the reproduction of criminal organization, it is crucial to explore such dimensions as local culture, politics and economics. How instrumental is the globalization of organized crime? How relevant are such factors as local culture as well as utilitarian interests? These questions are crucial if one wants to understand how it is possible that such social 
phenomena as organized crime can expand outside their local context without 'forcing' the new social environment into their acceptance.

Rocco Sciarrone (2011), a sociologist teaching at the University of Turin, draws on the category of social capital developed by Mark Granovetter (1983) to shed a light on the ways in which criminal organizations expand their activities from traditional areas, that is their areas of origin, to non-traditional areas, or the new places into which they move. The definition of social capital refers to the relational network that shapes either individual or collective lives. It is made of strong ties, which refer to family, kinship, territory-based bonds, and weak ties, a domain encompassing professional, recreational and all the functional bonds. Sciarrone, in analysing the growth of the Calabrian 'Ndrangheta both in northern Italy and abroad, shows how whereas strong ties matter in traditional areas - as kinship, territory and family allow criminal organizations to tighten those bonds, allowing them to hold their areas of origin in a firm grasp - weak ties are more suitable for expansion in non-traditional areas. For example, accountants or lawyers who tell the Mafioso the names of local firms who are experiencing hardship, so as to require a 'helping hand' from these criminal organizations, are the kind of weak tie needed to expand the range of activities of the Mafioso. Moreover, professionals also help the mobs to disguise themselves as legal actors, by setting up apparently legal firms whose official owners are bogus individuals found in the local context. All the parties draw advantage from such interactions: professionals who act as consultants and can claim a payment from their clients, entrepreneurs whose activity is rescued by the investment provided by criminal organizations, and, of course, the mobs themselves. Legal actors, in the event that they might be questioned by the police, might argue that they did not know the real activity of the client, and that they were acting either as consultants or as partners.

Sciarrone calls the areas of interaction between legal and illegal actors the grey area, to be distinguished from the white area, i.e. the entirely legal context, and the black area, i.e. the domain of entirely criminal interactions. An important point made by Sciarrone is that the actors who, in non-traditional areas, operate in grey areas are local actors who seek advantage by their interactions with criminal organizations. The idea of contagion proposed by Diego Gambetta is, by this token, ruled out. Moreover, Sciarrone widens the theoretical perspective proposed by Federico Varese: whereas the latter proposes a view that is based on the weakness of local society, focusing his analysis on the point of view of the Mafioso, the former proposes an interpretation based on the advantage local societies foresee in accepting the investments of criminal organizations to increase their gains. Sciarrone's analysis of global crime is therefore more focused on the strengths of local society. As a consequence of this, global crime can expand in every local context, regardless of the social fabric. All the local actors who consider it profitable to run businesses with criminal organizations will be keen to welcome them.

In moving from sociology to criminology, discussion on global crime revolves around two approaches. Vincenzo Ruggiero $(1996,2016)$ argues that it does not 
make sense to differentiate between clean and dirty economics. Firstly, because illegal actors provide legal actors with the wide range of goods and services they demand: drugs, prostitution, labour market control, gambling are demanded by 'clean' society. Secondly, because the organization of illegal economics marches at pace with legal spheres. The same organization, the same aim (profits), make the legal and the illegal two faces of the same coin. Finally, money gained in illegal markets is invested, recycled and spent in the legal markets, regardless of its origin. Globalization makes the borders between legal and illegal activities more and more blurred. Deregulation, as well as the increasing globalization of markets, provides more room for the increase of crime on a global scale, as there are more and more opportunities for investments, as well as for money laundering. Global crime also keeps pace with global markets through the creation of network-based organizations, involving both legal and illegal actors, which is typical of contemporary capitalism. Further, David Nelken (1998), though agreeing with Ruggiero on the expansion of global crime in relation to the globalization of markets, does not agree with the idea that worldwide economic integration brings about the shrinking of the role of states. National governments are always the focal point of penal policies, and still have a military force. Since globalization cannot completely overcome states as locally specific entities, as well as the local economic peculiarities, Nelken suggests a strategy to fight global crime inspired by the old ecologist slogan 'think globally, act locally'.

The approaches we have discussed here denote some common peculiarities: (1) the issue of the relation between the legal and illegal worlds appears to be crucial. Most of the sociologists, as well as Nelken, take up this point, with Ruggiero proposing a critical approach. (2) Can crime become global? Whereas Sciarrone, Nelken and Ruggiero are positive about it, Gambetta is sceptical, and Varese tries to suggest some specific conditions under which crime can expand. (3) What is the role of the state? Most of the authors agree with Gambetta that the more the role of central states shrinks, the more crime becomes global. Sciarrone oversees this problem, as he focuses on the grey area; Nelken thinks that states will never lose their prerogatives, and this can help in forging anti-crime politics. These are some of the points which make up the discussion about global crime that follows. Of course, discussions about global crime are not restricted to those of organized crime. As well as organized crime, this volume explores some of the wider complexities of global crime, and highlights both the acts and the actors involved and the contexts that sustain these activities.

\section{Key themes in thinking through global crime}

If there is a defining feature of the chapters in the volume it is their diversity. The study of global crime as it is currently practised spans multiple disciplines. This is something we were keen to capture in this volume, so you will find material here from disciplines including criminology, geography, legal studies and sociology, for example. Similarly, we were keen not to impose any theoretical or methodological 
restrictions on the authors of individual chapters collected here. We feel that the chapters in this book can then reflect the range and richness of perspectives that critical scholars, writing broadly from a social science perspective, are currently bringing to questions and issues of global crime.

However, despite this diversity there are a number of strong common themes and concerns that emerge across these chapters. The first theme, and one that is common to all of the chapters, is the complex relationships between legal and illegal, licit and illicit and the role of space in shaping these contingencies (see also Chiodelli et al., 2017). These are questions fundamental to the study of any crime but they are especially prescient where crime is now routinely networked across international spaces characterized by, at times, radically different regulatory, legal and social contexts. What might be considered illegal in one space might be legal, if perhaps illicit, in others. These questions form a central aspect of the chapter by Ray Hudson but are also explored explicitly in different contexts by Rosalba Altopiedi, Craig Martin and Majid Yar among others. A key aspect of the complex relationships between the legal and illegal and the licit and illicit is their intertwining through circuits of circulation within contemporary capitalism and the exploitation of these circulatory infrastructures, physical and virtual, by both licit and illicit actors, although such blunt categorizations are themselves problematic. Again, Ray Hudson and Craig Martin explore these issues in their chapters, as does Jo Large through her discussion of transnational markets in counterfeit goods (see also Gregson and Crang, 2017; Nordstrom, 2007).

There has been a tendency within discussions of globalization generally, and particularly of transnational crime in a global age, to produce overly globalist renditions of these processes and relations (see for example Jamieson, 1995; Robinson, 2002; Shelley, 2006; Sterling, 1994 and critical reactions to in Hall, 2018: 7; Wright, 2006: 159-160) inattentive to their local contours, the enduring grounded-ness of criminal actors and to the continued presence of the state within all this. This is something that Dick Hobbs has long been critical of $(1998,2013)$ and something he returns to in his chapter in this volume. Within this volume, then, we are also reminded of the enduring importance of the state in, for example, maintaining power asymmetries exercised in the normative definitions of legality and illegality, in exercising violence and practising criminality (explored in the chapters by Matt Clement, Daniel Mitchell and Svetlana Stephenson in very different contexts) and in the creation of multiple 'black sites', spaces beyond the law and in the discursive power of official constructions of crime (see the chapters by Daniel Mitchell and John Lea). In their chapters, Rosalba Altopiedi and Majid Yar also explore the significances of the state in the contexts of environmental crime and cyber-crime. The chapters here ground us in some of the realities of globalization and remind us not to get caught up in some of its weightless and frictionless fantasies. Mention of the state also raises questions of the challenges of the governance, surveillance, regulation, policing and securitization of transnational spaces in times of hyper-circulation and the limitations of extant models of doing so. These are themes considered here by authors such as Ray Hudson, Dick Hobbs, Majid Yar, Craig Martin and Jo Large. Further, as 
John Lea and Daniel Mitchell remind us in their chapters, these are processes prone to politicalization in pursuit of the interests of the powerful.

A number of authors in this volume - Rosalba Altopiedi, Jo Large and Daniel Mitchell, for example - advocate that we embrace the notion of harm in our discussions of many of the processes this book explores, as this raises ontological questions about what we should consider criminal. Harm is a concept that has gained increasing purchase within criminological discourse in recent years, and it captures the consequences of acts that are not formally criminal but that produce significant negative externalities, typically highly uneven in their social impacts. These include incidents of state and corporate crime (scandals such as the disaster at the Union Carbide Plant in Bhopal, India, in which 500,000 people, most of whom were housed in the informal settlements around the plant, were exposed to a leak of methyl isocyanate gas in December 1984, for example, are discussed by Rosalba Altopiedi) but also include the more routine operations of states and economies that generate social and environmental harm. The concept of harm as explored by Altopiedi and other authors here highlights the centrality of the illegal and illicit, which is woven into, and indeed even constitutive of, the political and economic mainstream, and debunks the myth that harm and crimes are purely external threats. This is particularly significant in the current age where much political discourse about globalization is suffused with imagined threats from various geographically or discursively externally located others.

The final point that we would like to make about all of the chapters here is that they show the value of adopting a critical, rather than a technical, legalistic or administrative, approach to understanding global crime. These points are made explicitly by some authors such as Rosalba Altopiedi, Matt Clement, Nicholas Groombridge, Dick Hobbs, Jo Large, John Lea and Daniel Mitchell, and they are inherent in all of the chapters within the volume. Critical perspectives highlight to us questions of power and the challenges of theorizing crime, harm and transnationality, which are central to much of the analysis advanced by the authors in this volume.

A final hope is that this volume invigorates discussion about global crime beyond its traditional disciplinary homes and across disciplinary boundaries. We very deliberately invited authors from disciplines that have traditionally said little about transnational and global crime to contribute to this volume. We encouraged contributors from different disciplines to engage in dialogue as they developed and wrote their chapters. Many of the issues that are discussed in this volume, we feel, are simply too significant and too pressing to be the preserve of a singular discipline. The disciplinary make-up of this volume reflects this belief.

\section{References}

Blok, A. (1974). The Mafia of a Sicilian Village, 1860-196o: A Study of Violent Peasant Entrepreneurs, Cambridge: Waveland Press. 
Chiodelli, F., Hall, T., Hudson, R. and Moroni, S. (2017). 'Grey governance and the development of cities and regions: the variable relationship between (il)legal and (il)licit', in Chiodelli, F., Hall, T. and Hudson, R. (eds) The Illicit and Illegal in the Development and Governance of Cities and Regions: Corrupt Places, Abingdon: Routledge, pp. 1-19.

Gambetta, D. (1993). The Sicilian Mafia: An Industry of Private Protection, Harvard, MA: Harvard University Press.

Granovetter, M. S. (1983). 'The strength of weak ties', The American Journal of Sociology, 78 (6), 1360-1380.

Gregson, N. and Crang, M. (2017). 'Illicit economies: customary illegality, moral economies and circulation', Transactions of the Institute of British Geographers, 42 (2), 206-219.

Hall, T. (2018). The Economic Geographies of Organized Crime, New York: Guilford.

Hobbs, D. (1998). 'The case against: there is not a global crime problem', International Journal of Risk, Security, and Crime Prevention, 3 (2), 139-146.

Hobbs, D. (2013). Lush Life: Constructing Organized Crime in the UK, Oxford: Oxford University Press. Jamieson, A. (1995). 'The transnational dimension of Italian organized crime', Transnational Organized Crime, 1 (2), 151-172.

Napoleoni, L. (2005). Terror Incorporated: Tracing the Dollars Behind the Terror Networks, New York: Seven Stories Press.

Nelken, D. (1998). Globalizzazione del Crimine e Giustizia Penale, Dei Delitti e delle Pene, 2/3, 64-77.

Nordstrom, C. (2007). Global Outlaws: Crime, Money, and Power in the Contemporary World, Berkley, CA: University of California Press.

Robinson, J. (2002). The Merger: The Conglomeration of International Organized Crime, Woodstock and New York: The Overlook Press.

Ruggiero, V. (1996). Organized and Corporate Crime in Europe, London: Routledge.

Ruggiero, V. (2016). Crimes of the Powerful, Oxford: Oxford University Press.

Santino, U. (2016). Mafia and Antimafia, London: IB Tauris.

Santino, U. (200o). Storia del Movimento Antimafia. Dalla Lotta di Classe all'Impegno Civile, Rome: Editori Riuniti.

Scalia, V. (2010). 'From the octopus to the spider's web. The structural transformation of the Sicilian Cosa Nostra', Trends in Organized Crime, 13 (4), 283-297.

Scalia, V. (2016). Crime, Network and Power: The Structural Transformation of the Sicilian Cosa Nostra, Basingstoke: Palgrave Macmillan.

Sciarrone, R (2011). Alleanze nell'Ombra, Rome: Donzelli.

Shelley, L. (2006). 'The globalization of crime and terrorism', eJournal USA, 11 (1), 42-45.

Sterling, C. (1994). Crime Without Frontiers: The Worldwide Expansion of Organised Crime and the Pax Mafiosa, London: Warner Books.

Varese, F. (2011). Mafias on the Move, Princeton, NJ: Princeton University Press.

Wright, A. (2006). Organised Crime, Cullompton, UK: Willan. 